\title{
Editorial
}

\section{Education and Health System Collaboration are Indispensable in Vaccination Coverage}

\author{
Chengjun Sun, PhD*
}

School of Management and Economics, Kunming University of Science and Technology, 253, Xuefu Road, Kunming, Yunnan 650093, China

\section{"Corresponding author}

Chengjun Sun, PhD

Assistant Professor, School of Management and Economics, Kunming University of Science and Technology, 253 Xuefu Road, Kunming, Yunnan 650093, China

E-mail: cjunsun@gmail.com

\section{Article Information}

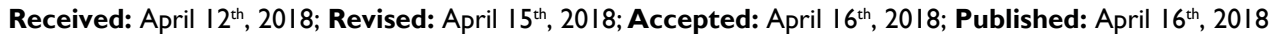

\section{Cite this article}

Sun C. Education and health system collaboration are indispensable in vaccination coverage. Vaccin Res Open J. 20I8; 3(I): el-e3. doi: I0.I7I40/VROJ-3-e005

$\mathrm{T}$ he practice of immunization dates back hundreds of years.

Over the $18^{\text {th }}$ and $19^{\text {th }}$ centuries, systematic implementation of mass smallpox immunization culminated in its global eradication in 1979 . The $20^{\text {th }}$ century saw great successes at developing vaccines and reducing the burden of infectious diseases such as yellow fever, hepatitis B and influenza. ${ }^{1}$

Despite the achieved success of vaccination, rumors about vaccine/vaccination have long circulated or perpetuated in communities. For instance, vaccination can cause autism ${ }^{2,3}$; mercury in vaccines acts as a neurotoxin ${ }^{3}$; vaccines are a ruse to sterilize children ${ }^{4}$; vaccines are contaminated with human immunodeficiency virus (HIV). ${ }^{4}$ In places where illiteracy is high and access to information is limited, these rumors are hard to debunk such that the populace is prone to accepting anti-vaccine "facts".

Education is imperative to battle rumor and resistance to vaccine campaigns. For childhood diseases, healthcare professionals may get trained and help start or continue conversations with parents when they have questions or concerns about their children's vaccines, and let them understand the risks and responsibilities if they choose not to vaccinate. ${ }^{5}$ An alternative way to disseminate educational information is communicating with media. The focus is that the mass media communicate the key messages about vaccine safety to the public, including the counteracting of negative rumors, and keep the public well informed. ${ }^{6,7}$

It's time for health systems to take actions in collaboration for vaccination coverage. Public health systems are typically administered at political geography levels: counties, provinces, states or countries. However, infectious diseases ignore borders and thus mobility-induced interconnections between administrative units have consequences. Because of a vaccine scare starting in $2002,{ }^{8}$ authorities in the northern Nigeria state of Kano interrupted polio vaccination in 2003-2004. ${ }^{9,10}$ This occurred in a context that neighboring countries had unideal polio vaccine coverage; (Figure 1). ${ }^{11}$ Vaccinations resumed in July the same year, ${ }^{12}$ but between the official interruption and the longer lasting public distrust, the

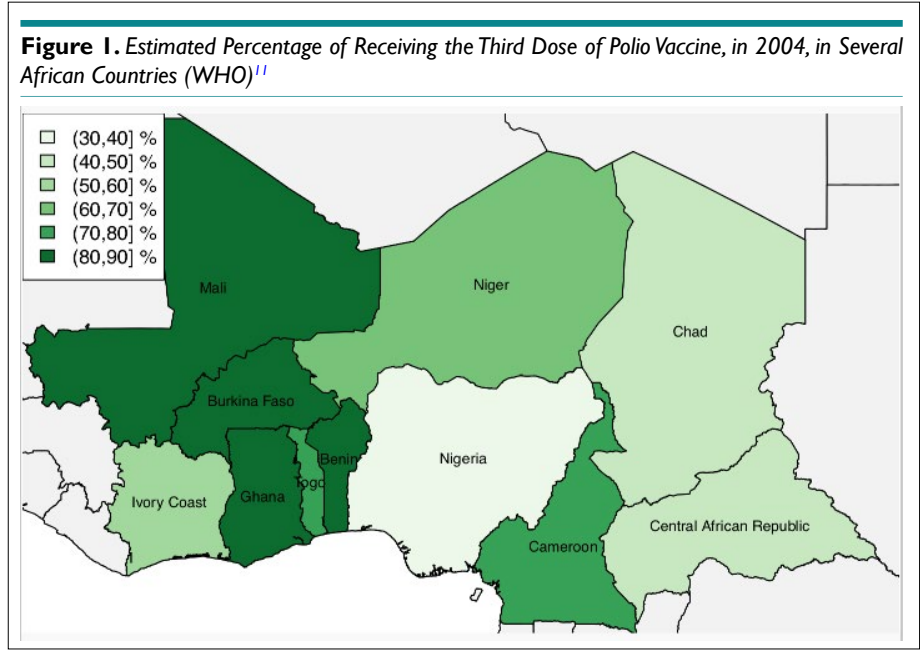



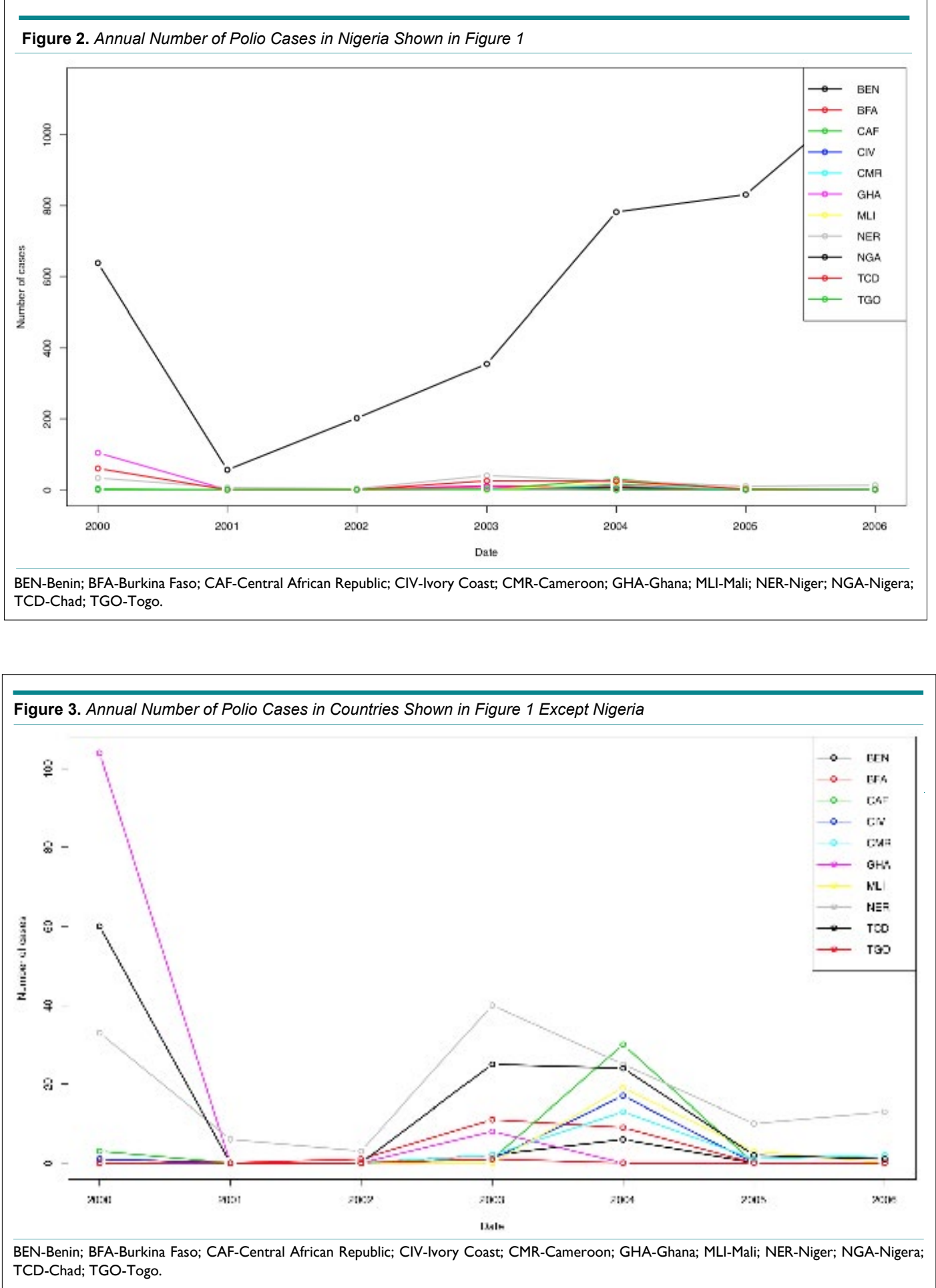

damage was done: cases with poliovirus in Nigeria went from 56 in 2001 to 355 in 2003, climbing to 782 in 2004, 830 in 2005, and peaking at 1122 in $2006^{10}$ (Figure 2), but also in close countries such as Cameroon. ${ }^{13}$ The effect is clearly visible in Figure 3.

In general, vaccine education and health system collaboration are beneficial to communities in disease prevention and con- trol. Parents should be educated about each vaccine and the role it plays in the well-being of their children, and accept the concept of individual immunity as a contribution to community well-being. Health systems, especially in less developed areas, should promote international and/or interregional collaborations in vaccination coverage to combat/eliminate the vaccine-preventable diseases. 


\section{ACKNOWLEDGEMENT}

The author acknowledges financial support from the project of KMUST for Fostering Talents in provincial level (KKSY20 1608050) and the project of Yunnan Education Department (2016ZZX055). The author would like to acknowledgement Kunming University of Science and Technology research facility and support.

\section{REFERENCES}

1. Greenwood B. The contribution of vaccination to global health: past, present and future. Philos Trans R Soc Lond B Biol Sci. 2014; 369(1645): 20130433. doi: 10.1098/rstb.2013.0433

2. Wakefield AJ. MMR vaccination and autism. Lancet. 1999; 354(9182): 949-950. doi: 10.1016/S0140-6736(05)75696-8

3. Mnookin S. How Robert F. Kennedy, Jr., Distorted Vaccine Science. Scientific American: Medicine. 2017; Web site. https://www. scientificamerican.com/article/how-robert-f-kennedy-jr-distorted-vaccine-science1/. Accessed April 11, 2018.

4. Hussain SF, Boyle P, Patel P, Sullivan R. Eradicating polio in Pakistan: An analysis of the challenges and solutions to this security and health issue. Global Health. 2016; 12: 63. doi: 10.1186/ s12992-016-0195-3

5. Suryadevara M, Bonville CA, Ferraioli F, Domachowske JB. Community-centered education improves vaccination rates in children from low-income households. Pediatrics. 2013; 132(2): 319
325. doi: $10.1542 /$ peds.2012-3927

6. Brunson EK. The impact of social networks on parents vaccination decisions. Pediatrics. 2013; 131(5): e1397-e1404. doi: 10.1542/ peds.2012-2452

7. Jegede AS. What led to the nigerian boycott of the polio vaccination campaign? PLoS Medicine. 2007; 4(3): e73. Web site. https://www.ncbi.nlm.nih.gov/pmc/articles/PMC1831725/pdf/ pmed.0040073.pdf. Accessed April 11, 2018.

8. Raufu A. Polio cases rise in Nigeria as vaccine is shunned for fear of AIDS. BMJ. 2002; 324(7351): 1414.

9. Olusanya B. Polio-vaccination boycott in Nigeria. Lancet. 2004; 363(9424): 1912.

10. Cheng MH. Nigeria struggles to contain poliomyelitis. Lancet. 2008; 372: 1287e1290.

11. WHO. Poliomyelitis (Polio) immunization coverage. 2004. Web site. http://www.who.int/gho/immunization/poliomyelitis/ en/. Accessed April 11, 2018.

12. Fleck F. Nigerian state of Kano resumes polio vaccination. BMJ. 2004; 329(7457): 70. doi: 10.1136/bmj.329.7457.70-d

13. Endegue-Zanga MC, Sadeuh-Mba SA, Iber J, et al. Importation and outbreak of wild polioviruses from 2000 to 2014 and interruption of transmission in Cameroon. J Clin Virol. 2016; 79: 1824. doi: 10.1016/j.jcv.2016.03.025 